\title{
DA FILOSOFIA DA CLASSIFICAÇÃO À CLASSIFICAÇÃO BIBLIOGRÁFICA ${ }^{1}$
}

\section{Leiva Nunes \\ Maria de Fátima Gonçalves Moreira Tálamo}

\section{Resumo:}

A Classificação é uma função importante para a funcionalidade dos sistemas de informação pois possibilita seu compartilhamento. Pode ser reconhecida como matricial, quando outras funções advêm dela. Ela é motivo de estudos desde a Antiguidade, uma vez que todo ato humano promove a distribuição em classes e pode ser inserido em uma delas. Porém os sistemas de classificação bibliográfica existentes não suportam o volume informacional, o que compromete a recuperação no momento da busca por informações. Há necessidade de métodos de tratamento dessas informações que tornem viáveis as respostas das organizações de documentos. O planejamento prévio dos procedimentos para garantir de forma acessível a informação necessita de observações. O usuário é o alvo principal desse sistema e portanto as classificações bibliográficas devem responder à necessidade do mesmo. As mudanças são constantes e necessárias. E os sistemas de classificação necessitam aprofundar a teoria dos conceitos e das categorias para auxiliar a representação do conhecimento. Ainda necessita de estudos aprofundados por pesquisadores da área, visto que o aumento dos acervos e das informações digitais criou uma nova realidade que assim o exige. Entretanto, os sistemas de classificação existentes têm tido dificuldade de acompanhar a crescente evolução do conhecimento, causa do aumento de informações que nem sempre têm sido recuperadas com êxito pelos pesquisadores.

\section{Palavras-chave:}

Classificação Decimal de Dewey. Classificação Decimal Universal. Sistemas de classificação. Conceitos de classificação.

\section{FROM CLASSIFICATION PHYLOSOPHY TO BIBLIOGRAPHIC CLASSIFICATION}

\begin{abstract}
:
Classification is an important function for the transparency and sharing of information. It can be known as matrix, when others functions come from it. And it has always been a preoccupation since ancient times, because all human action is classified. But, the existing bibliographic systems don't stand the informational volume, which causes deficiency of information retrieval in the moment of the search. Information treatment methods that make possible the answers for documents organization are needed. Also, a previous planning of procedures to guarantee accessible ways to information needs observations. The user is the principal goal of this system and it is understood that the bibliographic classification must answer his needs. The changes are constant and necessary. The classification systems need to deepen the concepts and categories theories to help the knowledge representation. It needs deeper studies of researchers of this area, given that the growth of collections and digital information created a new reality that demands it. However, the existing classifications systems have had difficulty to follow the growing evolution of knowledge, causing difficulties for the researchers to retrieve the volume of information successfully.
\end{abstract}

\section{Keywords:}

Dewey Decimal Classification. Universal Decimal Classification. Classification Systems. Classification Concepts.

\footnotetext{
${ }^{1}$ Este trabalho conta com o apoio da CAPES
} 


\section{Introdução}

Ao estudar os sistemas de classificação e a sua importância nota-se que os mesmos apresentam limites no tratamento da informação. Com o objetivo de identificar os fundamentos de tais limitações, discorre-se sobre as alterações das classificações ao longo dos tempos, caracterizando-se sua dinâmica evolutiva a partir do entendimento do conteúdo do documento e do seu uso pelo usuário. Reconhece-se com isso que a classificação como instrumento de representação do conhecimento não cumpre a função de recuperá-lo. Procura-se entender os fatores que levam a rigidez das classificações bibliográficas, a par da dinamicidade das próprias classificações, e elencar os elementos que a elas integrados, possam contribuir para a sua evolução.

Estudos comprovam a dificuldade de uso de biblioteca pelo usuário e a conclusão a que se chega é que a classificação bibliográfica não contempla amplamente a busca e recuperação da informação desejada. Diversos pesquisadores desse assunto estabelecem ligações, fronteiras, modos de aproximação de idéias, verbal e notacional para ordenação dos documentos nas estantes, quando distribuem as classificações bibliográficas conforme a finalidade, ao dirigí-las para definição e hierarquização do conhecimento humano.

É necessário um estudo mais aprofundado para a verificação de pontos positivos e negativos de cada sistema e a busca de conceitos utilizados pelos pesquisadores da área, auxiliam na familiaridade do problema proposto, com vistas a torná-lo mais explícito.

\section{Filosofia da Classificação}

Na sua trajetória o homem transforma todas as suas idéias em formas palpáveis e necessita selecionar, identificar e compor conceitos para elaborar base teórica para organizar seus estoques de conhecimento. Além disso, recorre também do raciocínio para que o espírito procure conhecer o pensamento verdadeiro e, para tal, necessita de critérios, leis e métodos e precisa distinguir uma coisa da outra.

Com a organização do conhecimento tem-se o processo análogo, pois é necessário determinar a clareza de conceito de um determinado documento, para que ele possa ser 
inserido em um conjunto de evidências. Os problemas de relações conceituais continuam sendo estudados, pois o contínuo aumento da quantidade de informação impõe dificuldades para a sua recuperação. Pode-se obter uma compreensão melhor de conceito, através de tesauros ou vocabulários controlados (DAHLBERG, 1978). Os conceitos são sínteses de enunciados verdadeiros sobre objetos do pensamento e levam à união ou à separação dos conceitos, através da definição de suas características, consideradas como elementos ou traços dos conceitos.

Os tipos de relações entre conceitos bem conhecidos são: relação gênero/espécie; relação de partição (todo/parte); relação de oposição; relação funcional. De acordo com formas categoriais e suas combinações tem-se uma organização de conceitos em qualquer área.

De acordo com a Lógica, o pensamento tende a elaborar conceitos não apenas corretos, mas verdadeiros e considera o conhecimento para chegar à verdade. Necessita da certeza para definir a verdade e distinguí-la do erro; e da evidência na qual a clareza do verdadeiro se impõe à adesão da inteligência.

O conhecimento filosófico é valorativo, não verificável, racional, sistemático, infalível e exato (MARCONI \& LAKATOS, 2000). Ele busca na razão humana os questionamentos para os problemas, a fim de estabelecer a diferença entre o certo e o errado. Adota o método racional como o procedimento dedutivo, não necessitando de experimentação. As idéias, as relações conceituais são os objetos de análise da filosofia.

Já o conhecimento científico é contingente, sistemático, verificável, falível e aproximadamente exato. A ciência necessita dos fatos reais e concretos para se apoiar e só afirma o que é autorizado pela experimentação, com o emprego de instrumentos e técnicas de observação.

Assim como as características são diferentes entre os vários tipos de conhecimento, os conteúdos dos documentos, quando estudados, podem integrar diversas áreas do conhecimento. Um mesmo documento pode ser descrito segundo vários aspectos, o que acarreta a coexistência de uma multiplicidade de conceitos ou classes. Separados por diferentes pontos de vista, cada um deles deve ser sistematizado, com a ordenação de vocabulário que os represente de forma eficiente, sustentado pela garantia literária e que 
seja reconhecido pelos membros de uma mesma comunidade. Tal forma de organização supõe a classificação.

Piedade (1977, p.61) distribui os sistemas de classificação conforme a finalidade, nos quais as classificações filosóficas (ou classificação das ciências, classificação do conhecimento, ou classificação metafísica) são dirigidas para a definição e a hierarquização do conhecimento humano. Já as classificações bibliográficas direcionamse à “ordenação dos documentos (livros, etc.) nas estantes ou nos arquivos” e à “ordenação das referências nas bibliografias ou das fichas nos catálogos”.

Dahlberg (1979, p.352) diz que “a antiga arte de classificar, tão antiga quanto a humanidade, apenas recentemente adquiriu uma base teórica adequada - base esta que nos permite presumir que ela progrediu do status de arte para o de ciência”. A organização dos documentos era feita de acordo com idéias já pré-concebidas, devido à ausência de uma esquematização, segundo o desenvolvimento do conhecimento.

“A primeira classificação sistemática das ciências de que temos notícia foi a de Aristóteles” (CHAUÍ, 2003, p. 226). O filósofo utilizou três critérios para classificar os saberes: critério da ausência ou presença do homem nos seres investigados, critério da imutabilidade e critério da modalidade prática. A partir do século XVII, os conhecimentos se dividiram em filosóficos, científicos e técnicos. E como a filosofia era considerada um saber diferente do científico, a tendência foi o desaparecimento dela nas classificações científicas e técnicas. Durante o século XIX, filósofos basearam-se, igualmente, em três critérios, a fim de propor classificações: tipo de objeto estudado, tipo de método empregado e tipo de resultado obtido (CHAUÍ, 2003). Segundo tais critérios e, ao mesmo tempo, com a simplificação das classificações anteriores, resultou a seguinte divisão das ciências: ciências matemáticas, ciências naturais, ciências humanas ou sociais e ciências aplicadas (usadas até os dias atuais).

A filosofia da classificação ainda tem muito que contribuir para o estudo e entendimento dos sistemas de classificação. A busca de linguagens modernas e conceitos que abrajam os temas atuais e a gama incessante de informações que surgem diariamente é um desafio para os estudiosos de tais sistemas.

\section{Sociologia da Classificação}

(c) Revista Digital de Biblioteconomia e Ciência da Informação,Campinas, v.7, n. 1, p. 30-48, jul./dez. 2009- ISSN: 1678-765X. 
Classificar é, portanto, “dividir em grupos ou classes, segundo as diferenças e semelhanças. É dispor os conceitos, segundo suas semelhanças e diferenças, em certo número de grupos metodicamente distribuídos” (PIEDADE, 1977, p. 09). É a ordenação de um conjunto de seres em pequenos agrupamentos, de acordo com características que os unem ou diferem de outros grupos. As leis de classificação devem fundamentar-se nesse princípio, para que sejam legítimas.

Os métodos, por sua vez, definem-se como o modo de proceder a uma operação (fazer, agir ou conhecer) para alcançar um fim projetado, isto é, consistem na ordem dos elementos de um processo para atingir um fim.

É necessário considerar não só a natureza dos objetos aos quais os métodos se relacionam, como também os pontos de vista sob os quais esses objetos podem ser considerados e relacionados com suas posições especiais nas subdivisões de suas classes.

A classificação é uma atividade social. De fato as classificações "são parte intrinsecamente constitutiva das sociedades” (COSTA, 1998, p.65). Utilizada sempre em toda parte e a todo o momento; atos classificatórios, julgados por características próprias com hierarquias que separam ou unem as heterogeneidades.

Nesse sentido, o ato de classificar é fundamento do ato de conhecer. Como observa Langridge (1977), para reconhecer o conhecimento alheio faz-se necessária a classificação, pois esta ocorre todo momento na vida do indivíduo e é igualmente necessária para que se proceda a uma comunicação eficiente. A classificação como princípio de organização está, portanto, presente em toda atividade humana e é base da interação social.

A classificação é uma função importante para a transparência e o compartilhamento de informações, as quais são caminhos para tomadas de decisões, para preservação da memória técnica e administrativa das organizações contemporâneas e também para o exercício da cidadania. É reconhecida como matricial, isto é, a partir dela que outras funções ou outras intervenções se consolidam. Desde o momento que seleciona o 
documento para guarda, o classificador trabalha com uma série de funções que discute a dimensão do conhecimento a qual permite a prioridade de procedimentos.

A classificação associa de um lado, todo o estoque informacional (acervo, arquivo) e, de outro, o receptor beneficiário do conjunto de informações (usuário). Infere-se disso que o ato de classificar promove a intermediação entre o sujeito e o objeto, já que a organização que produz sustenta o fluxo da informação. A classificação, portanto, desempenha papel fundamental em quase todas as áreas do conhecimento: mas, como sugere Sousa (2003, p.241), "o reconhecimento não permitiu ainda uma verticalização teórica sobre o tema, que aprofundasse o debate e encontrasse soluções consistentes para esta função”.

Com o grande volume de informações, sabe-se que os atuais sistemas não mais resolvem os problemas impostos por tal ordem e que há necessidade de mais discussões na área com a colaboração do conhecimento advindo de outras áreas.

O usuário, na sua exigência por maiores descobertas, tornou-se um cidadão ativo e ávido por informações técnicas e científicas, de acordo com suas necessidades e seu desenvolvimento.

Há algumas abordagens sobre a classificação quanto aos fundos e à ordem original, bases que fundamentam toda sua atividade. O princípio de respeito aos fundos é uma estratégia de depósito, o lugar onde se depositam os documentos que ali permanecem para serem encontrados por quem deles necessita. O princípio da ordem original é um princípio de classificação natural, a qual parte de princípios de divisão que exprime a ordem seguida pela natureza no meio das diferenças inevitáveis entre os seres. Observa as características comuns de seres distintos, elimina as diferenças, conserva as analogias e, a partir daí, constitui vários tipos de classificação (SOUSA, 2003, p. 251).

Desde a Antiguidade a preocupação em classificar e organizar todo e qualquer material em mãos faz presumir a importância que o homem deu em registrar a história, que é memória e cultura de qualquer povo. Ordenações diversas foram sugeridas por classes, séries, corpos, tamanhos e cores. Rupturas de vários sistemas fizeram surgir teorias novas de classificações. A classificação, devido a seu formato e a seu tratamento, e com a aquisição de postulados, é causa de estudos, e torna-se a representação temática do 
conhecimento. Ainda necessita de estudos aprofundados por pesquisadores da área, visto que o aumento dos acervos e das informações digitais criou uma nova realidade que assim o exige.

Atualmente, há pesquisadores na Europa e Estados Unidos, preocupados em analisar esses problemas. Há necessidade de métodos de tratamento dessas informações que tornem viáveis as respostas das organizações dos documentos. Precisam-se planejar previamente todos os procedimentos pelo quais passarão estes materiais e configurá-los com a tecnologia que se apresenta a fim de facilitar o acesso às informações, bem como ao alvo principal, o usuário, que está inserido na sociedade.

A Sociologia das classificações tem fundamento na filosofia da classificação e seus conceitos. As diversas sociedades existentes são agrupadas de acordo com esses conceitos e com a empatia entre seus pares com objetivos comuns.

\section{As Classificações Bibliográficas: exemplos e limites}

É importante, realmente, observar a classificação enquanto fenômeno social, pois todo homem classifica em todas as instâncias e todo momento, tanto os objetos quanto as pessoas, como diz Costa (1998, p.66):

\footnotetext{
Encontramos inúmeros exemplos de classificações inscritas e actuantes nos mais variados domínios das relações sociais, tal como se nos apresentam no quotidiano. Basta pensar na maneira como as pessoas tratam umas as outras, ou se referem a terceiras, atribuindo estatutos de superioridade ou inferioridade social, considerando umas distintas e outras vulgares, umas sérias e outras desonestas, umas competentes e outras incapazes, umas merecedoras de mais respeito e outras de menos, e por aí afora. (COSTA, 1998, p.66).
}

Por isso, o autor acima citado considera como classificações sociais aquelas organizadas por pessoas, mas que envolvem a sociedade para atender às necessidades de organização e de comunicação.

Entende-se, nesse sentido, que a classificação bibliográfica responde simultaneamente, a uma necessidade de organização interna das unidades de informação quanto de organização que vise à comunicação dos conteúdos armazenados com seus usuários. 
Observa-se, facilmente, na hierarquia da organização sistemática dos conteúdos dos documentos, uma análise dos conceitos presentes nesses conteúdos, bem como os tipos de relação que destes fazem parte, ao estabelecerem-se comparações de semelhanças ou diferenças, ao enunciar o objeto, e ao abranger todos os detalhes para classificá-los.

Quando se aplicam os princípios de análise clara e objetiva, após a descrição geral do documento, utiliza-se um sistema de classificação, já previamente ordenado em classes e subdivisões, a fim de validar os conceitos encontrados analiticamente, bem como para representar o conhecimento ou a informação.

Numa abordagem dedutiva, vê-se a classificação de documentos, dividida em categorias pré-existentes, mantidas pelos sistemas de classificação.

Sob esse esquema já pré-ordenado poder-se-ia sugerir, para a classificação, uma nova abordagem, visto que se reconhece o potencial que transporta para a comunicação da informação. Dahlberg (1979, p. 352), sugere que novas pesquisas poderiam ser orientadas para:

a) análises de conceitos, especialmente combinação de conceitos; b) análises de valência dos verbos nas diferentes línguas e em diferentes áreas do conhecimento, que resultem no estabelecimento de fórmulas para ordem de arquivamento e de citação; c) tipologia das estruturas de frases classificatórias; d) comparações entre conceitos com o auxílio de definições, inclusive problemas de estrutura e de estruturação de definições; e) metodologia para o estabelecimento de tabelas de correlações entre conceitos em diferentes áreas do conhecimento; estrutura de léxicos intermediários; f) determinação de estruturas sintáticas notacionais para a formação de representações expressivas de conceitos, juntamente com seus complementos necessários e facultativos; g) identificação de problemas organizacionais e relacionados com os usuários, na aplicação de enunciados e elementos classificatórios; quais os casos em que se necessita um acesso mais genérico, ou mais apurado, ou o mais preciso possível? (DAHLBERG, 1979, p. 352).

Os sistemas de classificação deveriam utilizar análises conceituais de assuntos mais abrangentes, de acordo com os recursos hierárquicos que possuírem, através de uma definição melhor dos termos de indexação, ao relacioná-los com a análise desses assuntos, em diferentes níveis de abstração. Essa análise conceitual, como é subjetiva, pois depende da interpretação do classificador supõe-se que uma flexibilidade do sistema 
permitiria representações mais qualificadas do conhecimento, o que propiciaria que o usuário procedesse também a uma interpretação mais condizente com suas necessidades.

Da pré-ordenação das classes decorrem variações de representação de um mesmo documento, face aos diferentes sistemas de classificação.

Os exemplos abaixo atestam semelhante característica:

Título do documento: Conferência Internacional sobre Psicologia de Crianças Excepcionais

Assuntos: Psicologia- Crianças excepcionais - Conferência

Crianças excepcionais - Conferência

Excepcionais - Conferência

CDD (Classificação Decimal de Dewey): 155.45206

155 Psicologia

452 crianças excepcionais

06 conferência

CDU (Classificação Decimal Universal): 159.922.76:061.3(100)

159.922.76 Psicologia de crianças

061.3 Congressos / conferências

(100) internacional

Os exemplos demonstram que, de acordo com o modelo acima, os sistemas Classificação Decimal de Dewey (CDD) e Classificação Decimal Universal (CDU) estabelecem notações diferentes para o mesmo enunciado, através da observação dos esquemas préestabelecidos de origem. Na tentativa de determinar as características que envolvem a classificação, o classificador fica impossibilitado de fazer novo arranjo para o conteúdo da coleção. Essa subordinação instala uma tensão no ato de classificar, o que influi tanto no pensar do classificador quanto no da sociedade em que está inserido.

Enquanto indivíduo, o classificador não pensa sozinho e, para apresentar as idéias que lhe são naturais, necessita de interagir com o pensar do outro. Deve se colocar no lugar do 
outro para promover uma circulação de informação mais efetiva, segundo categorizações compartilhadas do mundo. Entende-se assim que a comunicação humana encontra-se fortemente associadas às classificações próprias de cada cultura.

Os sistemas sofrem mudanças ao longo dos tempos, pois novos assuntos surgem no imenso universo do conhecimento humano. Recebem sugestões dos pesquisadores de novos assuntos a serem inseridos nas tabelas, e as comissões se encarregam de fazer os novos acréscimos. As tabelas da CDD e CDU já sofreram correções e há uma variação de notação de uma edição para outra em alguns campos de assuntos, como, por exemplo:

O assunto: IRRIGAÇÃO

Notação 631.7 ------- na $19^{a}$ edição da CDD

631.587 --- na 20a edição da CDD

O assunto: GENÉTICA

Notação 575.1 ------- na 20a edição da CDD

576.5 ------ na $22^{a}$ edição da CDD

O assunto: ECOLOGIA

Notação 574.5 ------ na $20^{a}$ edição da CDD

577 --------- na $22^{a}$ edição da CDD

Porém os documentos classificados com as notações da 20a (vigésima) edição, ou de qualquer outra edição anterior, não serão reclassificados, pois essa medida seria inviável em bibliotecas ou centros de informação com milhares de volumes de documentos em qualquer suporte já classificados. Nesse sentido, pode-se afirmar que os sistemas de classificações são ciclos de tratamento de organização de documentos, nas estantes, para ordem e guarda, ao considerar as dificuldades encontradas pela codificação e decodificação na recuperação do documento.

No sistema da Colon Classification (CC), por sua vez, não existe notação préestabelecida, pois o sistema de facetas e categorias permite uma flexibilidade sensível onde o uso de letras maiúsculas, letras minúsculas, números arábicos, sinais como vírgulas, pontos, setas anteriores e posteriores, parênteses inicial e final levam a uma 
notação diferenciada, na qual os assuntos representam o momento do contexto em que estão inseridos.

\section{Exemplo:}

Título do documento: Inflamação nas pálpebras:

Notação:

L18511: 415

Assuntos:

Medicina

Visão - Doenças

Olho - Pálpebras - Doenças

L

Classe principal (Medicina)

18511

foco personalidade para pálpebra

:

símbolo de ligação para a faceta energia

4 faceta energia para doença

415

faceta energia para inflamação

Para o:

Título do documento: Catalogação de periódicos nas bibliotecas das indústrias

Notação:

242;46:55

Assuntos:

Bibliotecas - Periódicos - Catalogação

Bibliotecas - Indústrias - Catalogação

Periódicos - Catalogação

2

classe principal (Biblioteconomia)

42

foco em personalidade para tipo de biblioteca - industriais

;

símbolo de ligação para a faceta matéria

46

periódico - faceta matéria tirada da classe Generalia (classe 2)

:

símbolo de ligação para a faceta energia

55

catalogação - faceta energia

Na CC um mesmo assunto pode ser dividido em tipo ou material, com inúmeras possibilidades de subdivisão.

Como, por exemplo, na arquitetura de habitação:

(c) Revista Digital de Biblioteconomia e Ciência da Informação,Campinas, v.7, n. 1, p. 30-48, jul./dez. 2009- ISSN: 1678-765X. 
tipos de arquitetura: residências, casas de campo, apartamentos, vivendas, chácaras, sítios

material da arquitetura: de tijolo, de pedra, de cimento, de vidro, de madeira

Um tipo de arquitetura pode ser visto sob prismas diferentes, assim como sob diversos materiais, o que possibilita uma gama de facetas, que se interligam num novo universo de assunto.

\section{Análise das Variações}

As facetas permitem "acrescentar certos assuntos a outros obedecendo a uma série de características e ligando as facetas por símbolos pré-estabelecidos” (BARBOSA, 1969, p.174). O sistema de Ranganathan, que sustenta a CC, possui 42 classes principais, subdivididas em classes subordinadas e até com números vagos, isto é, lacunas, para que possa preencher com um novo assunto, quando tal se fizer necessário.

Como os sistemas de classificação são elaborados para relacionar idéias, objetos, proporcionando um mapa de categorias, classes e subdivisões a eles associados, os mesmos devem contemplar uma dinâmica que os tornem funcionais. Burke (2003, p.91) observa que “ocorreram importantes mudanças dentro do sistema de conhecimento acadêmico entre o Renascimento e o Iluminismo, tendências à 'redefinição do conhecimento"” o que mostra que a mudança faz-se necessária para reformular a classificação do conhecimento apresentada por sistematizadores ou classificadores e torná-la mais flexível.

A distribuição dos documentos em disciplinas é uma solução pragmática que não soluciona o problema dos conceitos dos documentos analisados os quais necessitam de aprofundamento teórico e visão apurada para concretizar-se como documento organizado e de fácil recuperação. Nota-se, dessa forma, que os diversos e sucessivos modos de classificação de documentos expressam a preocupação com os princípios relacionados à organização do conhecimento.

Embora os sistemas de informação operem com o refinamento da percepção do objeto, gerando mapas cognitivos da sociedade, as linguagens pré-coordenadas limitam a 
classificação aos limites do sistema e à visão do classificador, não refletindo, nesse sentido, a organização de conceitos da área do conhecimento em questão.

A inversão de assuntos, recurso utilizado em épocas passadas, e às vezes, até os dias atuais também não permitem recuperação do documento pelo usuário, pois este pode fixar-se em outra forma de expressar, diferente da adotada pelo classificador.

Na contemporaneidade com a ajuda de diversos softwares, podem-se fazer as operações boleanas and, or, not para estabelecer uma melhor relação entre os termos e, assim, tornar possível localizá-los. Mas tais operações supõem organização conceitual dos conteúdos dos documentos, e os sistemas de classificação não foram criados para recuperar a informação, uma vez que não fazem novas relações entre os termos. Nas pesquisas, os estudiosos vêem neles a maneira de ordenação do conhecimento.

Se a interação homem-computador assegurar uma consistência de dados, poderá ser conhecida uma classificação que corresponda a esta ausência de elo. Devido ao crescente volume de informações, os novos assuntos são colocados de forma nem sempre lógica, pois em inúmeras vezes não há uma classe que o encaixe perfeitamente. Os sistemas de classificações são apriorísticos, pois existem previamente ao documento e como não são flexíveis, as classificações não compartilham com a interdisciplinaridade. No entanto, essas são ferramentas de extremo valor na organização do conhecimento.

A International Society for Knowledge Organization (ISKO) “considera que os princípios teóricos da classificação e as pesquisas sobre tesauros podem ser utilizados na organização dos mais diversos sistemas gerais e específicos de organização e representação do conhecimento” (STRAIOTO, 2001, p. 49).

\section{Classificações Bibliográficas: organização dos sistemas}

Para a organização, o gerenciar e recuperar a informação existe em muitos sistemas de classificação, e além deles, os tesauros, as ontologias, os glossários e dicionários também o fazem. Os sistemas de classificação necessitam, portanto, recorrer à teoria dos 
conceitos, identificando elementos pertinentes para aproximá-los da tarefa de representação do conhecimento.

Precisam, de fato, acompanhar o incontrolável momento de "explosão de informação", pois é, neste ponto “do incontrolável na Internet”, que a Ciência da Informação necessita canalizar esforços para refinar o processamento da informação; caso contrário, o caos está declarado.

Os sistemas de classificação necessitam seguir as mudanças do ambiente que estão instalados, modificar-lhes as formas, e a maneira como estocam as informações, para filtrar qualidade.

Cada sistema de classificação existente foi criado para tentar organizar a informação. No entanto, cada modificação de um sistema para o outro na tentativa de mudanças, com quebras nas regras conhecidas, para o conhecimento da explosão daquele momento, trouxe à tona outros fatores que contribuíram para a formação de um novo sistema.

A cada quebra, ou ruptura um novo ambiente se impõe na tentativa de superar dificuldades existentes e não mais capazes de suportar o peso de tamanho número de informações.

Como se sabe que os sistemas de classificação são utilizados para a organização do conhecimento, faz-se necessária a existência de teorias mais detalhadas para que representem, realmente, o objeto a que almeja fazê-lo. Nesse sentido, a importância da linguagem e dos conceitos, bem como das categorias tornam-se relevantes.

Nota-se claramente, nos últimos tempos, que as classificações tornaram-se limitadas, e os usuários, mais exigentes. Os classificadores, passíveis de falhas, precisam acompanhar essa insatisfação ao buscarem nova qualidade de classificação, possivelmente baseada na ajuda mútua entre as pessoas da comunidade que vivem, ao integrar a sociedade científica com a sociedade comum. Ao partir da premissa de que o homem não trabalha sozinho, ele deve recorrer aos semelhantes para descobrir; modificar; obter; atingir; influenciar e produzir conhecimento. Precisa do conhecimento para gerir a si próprio e aos outros, para habilitar-se compreender e transmitir idéias e conduzir ao entendimento. 
Quando Ranganathan desenvolveu a Classificação por Facetas, e hoje se discute sua utilização com potencial de mudar a evolução do conhecimento, percebeu-se, claramente, a possibilidade de fragmentar um determinado assunto ou termo, em outros diversos aspectos, o que constitui uma vasta gama de assuntos correlatos, e elabora um mapa conceitual de qualquer área do conhecimento.

A classificação é feita para ordenar melhor as inúmeras questões que rodeiam a inteligência humana. Kuhn (2003) revela que periodicamente as Ciências esbarram em anomalias que precisam ser compreendidas para tornarem-se regras.

Se a Classificação se unir à Computação, à Sociedade, à Internet, à Web 2.0 e à Comunicação, poderá construir uma rede de sistemas de informações avançada integrados à transdisciplinaridade das áreas do conhecimento. A própria sociedade empreende uma luta desigual com os sistemas de classificação. À medida que eles operam com limitações no tratamento da informação, a sociedade realiza a busca das informações desejadas na internet e sente-se satisfeita com respostas, não raro, deficitárias ou destituídas de credibilidade. Compete aos classificadores aclarar as idéias e buscar recursos sólidos numa era que se caracteriza pelo caos informacional.

É provável que atualmente se busque uma renovada “quebra” de regras pré-estabelecidas, para dar vazão ao estoque de conhecimento que cresce e se altera de forma contínua.

Pesquisadores já constataram que, ao classificar um assunto, “a implicação do paradigma clássico é que todos os objetos em uma categoria são similares e equivalentes” (IYER, 1995, p.42). As propriedades destes objetos são partes semelhantes de um todo e, na associação revolucionária de termos, desencadeiam-se novas relações que originam outros termos os quais são ligados a outros, o que resulta em enorme cadeia de conceitos.

Aristóteles defendeu dez categorias em estudos de conhecimento e Ranganathan também o fez, embasado na teoria clássica do conceito e da categoria, onde o mundo real é estruturado em grupos hierárquicos com propriedades inerentes. A classificação bibliográfica necessita não só da elaboração dos conceitos para melhor representar seus assuntos, bem como das categorizações da análise documentária. 
Os sistemas de classificação são os lugares em que se instalam uma "tensão dialética”, conforme Lima (2007, p. 119). As terminologias da área em que se baseiam os tesauros, e os sistemas de classificações, supõem etapas de codificação e de decodificação dos assuntos que supõe a substituição da linguagem natural por uma linguagem controlada. A classificação bibliográfica tem a tarefa de organizar o conhecimento de forma acessível ao usuário, tarefa que não é levada a cabo fundamentada exclusivamente na classificação do conhecimento feita pelas cátedras nas universidades.

Os sistemas de classificação bibliográfica mais conhecidos (CDD, CDU, Colon Classification e LC) organizam o conhecimento de acordo com a classificação do conhecimento produzido pela sociedade em que atua. De geração em geração, o conhecimento só atinge sua dimensão social quando é registrado, organizado e recuperado pela sociedade.

\section{Considerações Finais}

No presente contexto a classificação necessita estabelecer procedimentos e diretrizes que definam um conjunto de relacionamento de termos de cada área de conhecimento, com conceitos validados para solidificar o processo de classificação de “assuntos”.

No momento da leitura do documento, há uma tensão clara e evidente na forma de classificar a definição dos termos, as características, as significações, os modelos mentais e os conteúdos do mesmo. Como a linguagem do usuário difere da linguagem do sistema, a informação de que o usuário necessita deve ser indicada com exatidão, para a concretização da recuperação da informação.

Até o momento, os sistemas de classificação mantiveram o relacionamento aristotélico de gênero-espécie, com ênfase à subordinação e subdivisões para baixo, numa ordem hierárquica as quais geram uma limitação na hora de combinar classes o e no tratamento de temas complexos. Esses sistemas de classificação são, até os dias atuais, ferramentas para a organização de coleções no acervo e, embora, mantenham-se prisioneiros de uma organização de conhecimentos datada do fim do século XIX, adquirem uma dimensão internacional. (Calcaly, S. et al, 1997) 
Assim, estima-se que a flexibilização das classificações depende de uma análise mais acurada do assunto em seus conceitos e relacionamentos, os quais contribuirão para substituir a rigidez as caracteriza por fundamentos sólidos. De fato, como observa Calcaly et al (1997, p. 137), “a existência e a perenidade de uma classificação estão estreitamente ligadas à sua capacidade de evoluir”.

Por fim, resta salientar que o conhecimento registrado e organizado gerencia e estabelece bases de produção para uma sociedade que abstrai desta organização esquemas lucrativos de política informacional. Tal fato gera uma necessidade urgente de atualização de bibliotecas e centros de documentação para a área da classificação, visando à melhor organização de gerenciamento da informação e à disseminação da mesma. Novos conhecimentos só podem ser gerados da transformação de informações, as quais arquivadas e recuperadas, dão vida a novos processos de informação. Todavia, esse arquivamento ou armazenamento de informações precisa estar em sintonia com o sistema de classificação adotado e a linguagem que o especifica.

O classificador deve ter como meta o trabalho orientado pelo conteúdo do documento, analisando e codificando a informação, através da determinação de conceitos para que o usuário possa receber a mensagem e decodificá-la de acordo com seu contexto cultural e informacional.

\section{Referências}

BARBOSA, A. P. Teoria e prática dos sistemas de classificação bibliográfica. Rio de Janeiro: IBBD, 1969. 441p.

BURKE, P. Uma história social do conhecimento: de Gutenberg a Diderot. Rio de Janeiro: Jorge Zahar, 2003. 241p.

CALCALY, S. ET AL. Dictionaire encyclopédique de l'ínformation et de la documentation. Paris: Nathan, 1997. 634 p.

CHAUÍ, M. Convite à filosofia. 13.ed. São Paulo: Ática, 2003. 424p. 
COSTA, A. F. Classificações sociais. Leitura, Lisboa, v.3, n.2, p.65-75, out. 1997/abr.1998.

DAHLBERG, I. Fundamentos teóricos-conceituais da classificação. Revista de Biblioteconomia de Brasília, Brasília, v.6, n.1, p.9-21, jan./jul. 1978.

DAHLBERG, I. Teoria da classificação, ontem e hoje. In: CONFERÊNCIA BRASILEIRA DE CLASSIFICAÇÃO BIBLIOGRÁFICA, 1972, Rio de Janeiro. Anais... Rio de Janeiro: IBICT/ABDF, 1979. v.1, p.352-370.

IYER, H. Classificatory structures: concepts, relations and representation. Frankfurt: Indeks Verlag, 1995. v.2. 230p.

KUHN, T. A estrutura das revoluções científicas. 7.ed. São Paulo: Perspectiva, 2003. 257p.

LANGRIDGE, D. Classificação: abordagem para estudantes de biblioteconomia. Rio de Janeiro: Interciência, 1977. 120p.

LIMA, V. M. A. A informação documentária: codificação e decodificação. Transinformação, Campinas, v.19, n.2, p.119-127, maio/ago. 2007.

MARCONI, M. A.; LAKATOS, E. M. Metodologia científica. 3.ed. São Paulo: Ática, 2000. 289p.

PIEDADE, M. A. R. Introdução à teoria da classificação. Rio de Janeiro: Interciência, 1977. 190p.

SOUSA, R. T. B. de. Os princípios arquivísticos e o conceito de classificação. In: RODRIGUES, G. M. ; LOPES, I. L. (Org.). Organização e representação do conhecimento na perspectiva da Ciência da Informação. Brasília : Thesaurus, 2003. p. 240-271. (Estudos Avançados em Ciência da Informação, 2). 


\section{ARTIGO}

STRAIOTO, A.C. A análise em facetas como dimensão teórica e prática na organização do conhecimento. 2001. 163 f. Dissertação (Mestrado em Ciência da Informação) - Faculdade em Filosofia e Ciências, Universidade Estadual Paulista, Marília, 2001.

\section{Leiva Nunes}

Formada em Biblioteconomia e mestrado em Ciência da Informação. Atualmente trabalha na Biblioteca Central da Universidade Federal de Viçosa - Viçosa/MG

Inunes@ufv.br

\section{Maria de Fátima Gonçalves Moreira Tálamo}

Bacharel em Lingüística pela Universidade Estadual de Campinas (1973), mestre e doutora em Ciências da Comunicação pela Universidade de São Paulo $(1982,1989)$.

Recebido em: 07/01/2008

Aceito para publicação em: jan/2009 